\title{
STUDIES ON FUCOIDAN AND ITS PRODUCTION FROM VIETNAMESE BROWN SEAWEEDS
}

\author{
Bui Minh Ly, Ngo Quoc Buu*, Nguyen Duy Nhut, \\ Pham Duc Thinh, and Tran Thi Thanh Van
}

Nha Trang Branch of Institute of Materials Science, VAST, Vietnam

Received 19 July 2005

\begin{abstract}
Sulfated fucans are among the most widely studied of all the sulfated polysaccharides of plant origin that exhibit biological activities in mammalian systems. In this report fucoidans from some Vietnamese Sargassum species such as S. polycystum, S. oligocystum, S. mcclurei, S. swartzii and denticaprum were extracted and fractionated on a DEAE-Sephadex A-25 column.

On the basis of chemical and spectral analyses, the fucoidan fractions obtained were found to be the sulfated fucogalactans containing sulfate ester groups and uronic acid, and composed essentially of fucose and galactose, as well as a minor amount of other sugars. The polysaccharide fractions were tested for anticancer activity. The primarily obtained results showed that all fucoidan fractions isolated from S. swartzii demonstrate bioactivity effects against cancer cells, while fraction F5 with a highest sulfate content exhibits the strongest antiinvasion activity. This indicates that sulfate content plays an important role in the anticancer activity of the brown algal fucoidans.
\end{abstract}

A laboratory scale pilot for fucoidan production from Vietnamese brown seaweeds has been set with a capacity of $500 \mathrm{~g}$ of crude fucoidan per day.

Keywords: Fucoidan, Apoptosis, Seaweed, Sargassum, Anti-invasion activity

\section{INTRODUCTION}

Global utilization of macroalgae is multi-billion dollar industry. Much of this is based on farming of edible species or on the production of agar, carrageenan and alginate. Of all seaweed products, hydrocolloids have had the biggest influence on modern sociaties. They are used in various industries which exploit their physical properties such as gelling, water retention and their ability to emulsify. Very little exploitation of products extracted from seaweeds appears outside the hydrocolloid industry. However, in recent years the pharmacists have started looking towards marine organisms, including seaweeds, in their search for new drugs from natural products. During the 1980s and 1990s compounds with biological and pharmacological activities were discovered in marine bacteria, invertebrates and algae. According to Ireland et al.

${ }^{*}$ Corresponding author e-mail: buu_nq@yahoo.com 
[1], marine algae have been the largest source of about $35 \%$ of the newly discovered chemicals between 1977-1987, followed by sponges (29\%) and cnidarians (22\%).

Substances that currently receive most attention from the pharmaceutical companies for use in drug development are sulfated polysaccharides. Some sulfated polysaccharides from red algae show antiviral activities towards viruses responsible for human infectious diseases [2], among which sulfated mannans and carrageenans were found to be effective against HIV, HSV types 1 and 2 and RSV (respiratory syncytial virus) [3]. Many studies have shown that uronic acidcontaining saccharide and laminaran in marine algae are effective immunostimulating agents for animals and plants, meanwhile some agaroids such as high molecular weight sulfate galactan and 3,6-anhydrogalactose from some Gracilaria spp. also have antiviral properties against HSV types 1 and $2[4,5]$.

However, among all these diverse sulfated polysaccharides, fucoidans appear to be the most prominent from the pharmaceutical view point. Fucoidans (sulfated fucans), a unique class of sulfated polysaccharides with highest pharmacological activities, are isolated mainly from brown seaweeds. Their composition varies with the species and geographycal origin, but fucoidans always contain essentially fucose, sulfate and uronic acids, with small propotions of galactose, xylose, arabinose and mannose [6]. Algal fucoidans are present in several orders, mainly Fucales and Laminariales, but also in Chordariales, Dictyotales, Dictyosiphonales, Ectocarpales and Scytosiphonales. In fact they are widely present among all the brown algae (Phaeophyceae) so far investigated. The only other sources of sulfated fucans known to date are marine invertebrates [7].

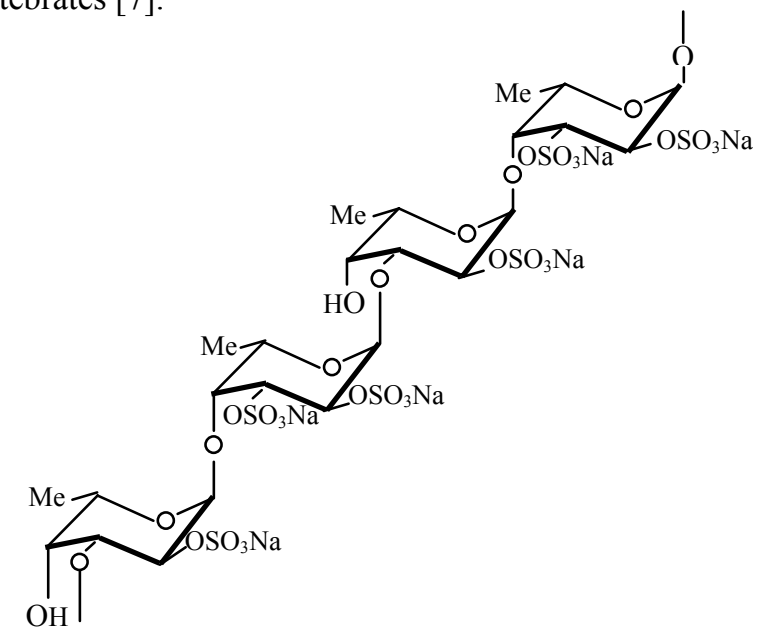

Fig. 1: A disaccharide repeating unit of a LMW fucoidan isolated from Ascophylum nodosum prepared by acid hydrolysis and partition chromatography [9]

The structures of algal fucoidans are usually complicated, because they are heterogeneous and branched with nonregular sulfation patterns, and may contain additional monosaccharide constituents or acetyl groups [8]. Nontheless, Chevolot and his team [9] have succeeded in isolating a disaccharide repeating structure of a low molecular weight fraction of the fucoidan from Ascophylum nodosum prepared by acid hydrolysis and partition chromatography, as shown in Fig.1:

$$
[\rightarrow 3)-\alpha-\mathrm{L}-\mathrm{Fuc}\left(2 \mathrm{SO}_{3}{ }^{-}\right)-(1 \rightarrow 4)-\alpha-\mathrm{L}-\mathrm{Fuc}\left(2,3 \mathrm{SO}_{3}{ }^{-}\right)-(1 \rightarrow]_{\mathrm{n}} \text {. }
$$


Because of their interference with molecular mechanisms of cell-to-cell recognition, algal fucoidans are potent blockers of a wide range of biological processeses. Thus, algal fucoidans are inhibitors of cell invasion by retroviruses such as HIV, herpes, cytomegalovirus, and African swine fever virus [10 - 12]; inhibit invasion of erythrocytes by Plasmodium falciparum merozoites and cytoadherence of parasitized erythrocytes to endothelial cells [13]; act as antiangiogenic agents [14]; block selectin-mediated cell-cell binding [15]; inhibit sperm-egg binding in diverse species, demonstrating antiproliferative properties etc [16 - 18].

Fucoidans possess exceptional pharmaceutical activities such as anticoagulant [19], antibacterial and antiviral [20, 21, 22], antithrombotic [23], antitumoral [24], antiinflammatory [25], antiproliferative [17], and antifertilizing [18]. They are also successfully used for prevention and treatment of such widespread diseases as high blood pressure, arthritis, diabetes and obesity. These bioactive properties largely depend on molecular weight sulfate content and position, as well as molecular structure of the polysaccharides [26].

The ongoing researches into fucoidan have conclusively demonstrated its ability to induce cancer cell apoptosis (programmed self-destructive cell death) in leukemia, stomach, colon and other cancers [27]. Unlike a necrosis which is a pathological cell death, an apoptosis is considered to be the death which is inherently programmed in genes of the cells themselves. Thus, it is believed that some external or internal factors trigger the activation of genes which program the apoptosis whereby a programmed death gene protein is biosynthesized and the cells themselves are decomposed by the resulting programmed death gene protein, and death is resulted.

The brown seaweed fucoidans exhibit growth-inhibiting effect against different cancer cells. It is well known that cancer cells are permitted to replicate because the immune system fails to recognize and destroy them. Fucoidan produces interleukin and interferon compounds in the immune system that inhibit malignant cell growth, thereby having an anticancer effect [28]. In light of these actions, fucoidan can play a pivotal role in our immune response to cancer and infection. In the tests using human bronchopulmonary carcinoma cells (lung cancer cells), fucoidan effectively blocked the G1 phase of cell division, interfering the growth of malignant tumors.

In spite of that five years ago one European patent [29] affirmed that "fucoidan has not been prepared industrially and sold yet although it is a material that is available to extremely extensive fields as stated above, the greatest reason is that a marine alga including the fucoidan abundantly has not been discovered", to date, there are many pharmaceutical companies in the world such as Sigma, LCR-Fucoidan, SeaVegg, Fucoidan QOL, The Lab Depot Inc.,Vitacorp International, Bodywork, Dextra etc., which produce fucoidans from brown seaweeds for supplying to the markets. Company Sigma sells its crude fucoidan isolated from Fucus vesiculosus at a price of $\$ 43.50$ for one gram, while The Lab Depot Inc.- at a price of $\$ 90.51$ for one gram as a laboratory chemical.

Vietnam has a coastline of about $3200 \mathrm{~km}$ with the climate varying from subtropical in the northern to tropical in the southern part of the country, very suitable for different seaweed species to grow. The total number of seaweed species along the coast is estimated to be nearly 650 spp., including about 230 Rhodophyta, 125 Phaeophyta, 145 Chlorophyta and 75 Cyanophyta. Among this algal diversity the brown seaweed genus Sargassum is the largest natural seaweed resource of Vietnam, including about 50 species. The annual production of Sargassum is estimated to over 4000 tons (dry wt.), but the harvesting and utilization of Sargassum in Vietnam still remains below the potential of the resource [30]. Until recently, the total amount harvested has only been 300 - 500 tons/year (dry wt.), which is used as a source for manufacturing alginate in small scale units and manure/fertilizer for the onion, garlic, chilies and sweet potato cultivation. 
This report presents some results of the studies on fucoidans and their production from Vietnamese brown seaweeds Sargassum targeting towards the contribution to public health care.

\section{EXPERIMENTAL PROCEDURES}

Samples collection: Brown algal Sargassum species were collected on the coast of Khanh Hoa province in june. The seaweed samples were washed with fresh water, sun dried, and air dried at room temperature, and then milled to powder.

Extraction: Crude fucoidans were extracted from the brown seaweed samples with an acidic solution $0.1 \mathrm{M} \mathrm{HCl}$ with a solid/liquid ratio $1: 10$ in the presence of $2 \mathrm{wt} \% \mathrm{CaCl}_{2}$ for alginic acid separation, and partially purified by cetylpyridinum chloride and ethanol precipitation, as described in [31]. For color and salt removing a dialysis process with ultrafiltration membrane was used. Block diagram for crude fucoidan extraction from brown seaweeds for analytical purposes is shown in Fig. 2.

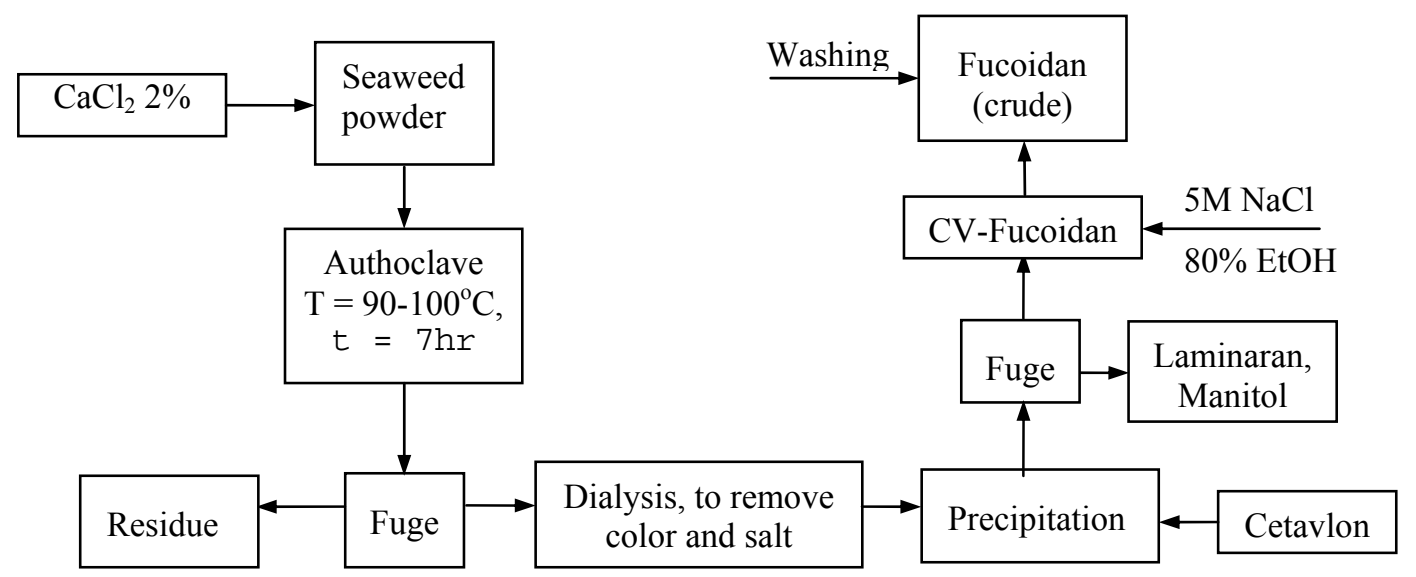

Fig. 2: $\quad$ Scheme for crude fucoidan extraction from brown seaweeds for analysis

Fractionation of fucoidan for analysis: Fractionation was carried out using anion-exchange chromatography with DEAE-Sephadex A-25 (Pharmacia) in $\mathrm{Cl}^{-}$form. An aqueous solution of crude fucoidan $(1.1 \mathrm{~g}$ in $50 \mathrm{ml})$ was applied to the column $(30 \times 1.7 \mathrm{~cm})$ and eluted with water followed by sodium chloride solution elution with increasing concentrations $(0.5,1.0,1.5,2.0,3.5 \mathrm{M}$ $\mathrm{NaCl}$ ) each time until the absence of positive reaction of the elute with phenol and $\mathrm{H}_{2} \mathrm{SO}_{4}[32]$.

Fucoidan dialysis. Fucoidan was dialyzed for 3 days against $0.1 \mathrm{M}$ pyridine acetate, pH 5 - 5.4, with a buffer change every day, using UF membrane cartridge with MWCO 15000, 50000, 100000 and $200000 \mathrm{Da}$.

\section{Carbohydrate and sulfate Analysis}

Total fucose was measured by the method of Dubois et al.[32].

Monosaccharide content was determined after hydrolysis (TFA, 2 M, 6 h). Hydrolysates were dried under reduced pressure. Monosaccharide concentrations were then measured by high performance anion-exchange chromatography with pulsed amperometric detection.

Sulfate content was measured using gelatin $/ \mathrm{BaCl}_{2}$ method after hydrolysis in $2 \mathrm{M}$ TFA for $6 \mathrm{~h}$ $[33,34]$. 
Uronic acid content was determined by the carbazole method using D-gluconic acid as a standard. Interference from hexoses in this assay was determined by use of controls containing the same ratio of component sugars as found in fucoidan. Differencies in the absorption characteristics of products derived from uronic acid and hexoses were used to determine the final uronic acid content [35].

Desulfation of the sulfated fucans was performed by solvolysis in dimethyl sulfoxide, as described for desulfation of other types of polysaccharides [31, 36].

Assay of anti-invasion activity. The ability of the cells to invade through Matrigel-coated filters was determined using a modified 24-well Boyden chamber (Corning Costar, Cambridge, MA, USA: $8 \mu \mathrm{m}$ pore size) The cells were seeded at a density of $2 \times 10^{4}$ cells in $100 \mu \mathrm{l}$ RMI containing $10 \%$ FBS in the upper compartment of transwell. To determine the effect of fucoidans, various concentrations of fucoidans were added to the upper compartment of transwell. After incubation for $24 \mathrm{hrs}$ at $37^{\circ} \mathrm{C}$ in $5 \% \mathrm{CO}_{2}$, the cells that not penetrated the filter were completely wiped out with a cotton swabs, and the cells that had migrated to the lower surface of the filter were fixed with methanol. And then the cells were stained with hematoxylin and eosin (Sigma), and counted in 5 randomly selected microscopic fields.

NMR spectroscopy. Samples were deuterium-exchanged by evaporating three times with $\mathrm{D}_{2} \mathrm{O}$ and then examined in solution $\mathrm{D}_{2} \mathrm{O}$ with acetone as an internal standard. The spectra were recorded at $25^{\circ} \mathrm{C}$ and $60^{\circ} \mathrm{C}$ by using Brucker $300{ }^{1} \mathrm{H}-\mathrm{NMR}$ spectrometer at the Anticancer Laboratory of Korean Research Institute of Biology and Biotechnology.

\section{Results and discussion}

Crude fucoidans from brown seaweed samples were extracted as described in Fig. 2 and then fractionated by ion-exchange chromatography on DEAE-Sephadex A-25. Yield and composition of fucoidan fractions isolated from Sargassum swartzii are shown in Table 1 and Fig. 3. All fucoidan fractions contained fucose as the major component sugar along with galactose as medium one and mannose, glucose, xylose, rhamnose and arabinose as minor ones, indicating that they are fucogalactans, but the proportion of these sugar components varies from one fraction to another. Fraction which was eluted with lower $\mathrm{NaCl}$ concentration was rich in uronic acid and poor in sulfate groups. On the other hand, fraction which was eluted with higher concentration of $\mathrm{NaCl}$ had a higher sulfate and lower uronic acid contents. The five fucoidan fractions could be grouped into two sets. The first set (F1, F2) is characterized by high percentages of uronic acid and low sufate content. The second one (F3, F4 and F5) is characterized by lower uronic acid and higher sulfate contents. These results indicated that crude fucoidan extracted from $S$. swartzii was heterogeneous with respect to not only molecular weight, sulfate and uronic acid contents, but also to sugar constituents. Similar results have reported for fucoidans from other brown seaweeds [37 - 39].

The structural components of sulfated fucans necessary for their biological activity studies have not been completely determined because of the fact that algal sulfated fucans are heterogeneous polysaccharides, which give complex NMR spectra with broad signals worsening resolution [40]. Fig. 4 illustrated a $\mathrm{H}^{1}$ NMR spectrum of the fucoidan fraction F4 isolated from $S$. mcclurei after solvolytic desulfation in a mixture $\mathrm{MeSO}_{4}-\mathrm{MeOH}-$ pyridine. Like many other brown algal fucoidans, fraction F4 had rather complex ${ }^{1} \mathrm{H}$ NMR spectra with broad signals. These signals include characteristic resonances of sulfated $\alpha$-L-fucopyranose residues such as broad signal between 5.0 and 5.4 ppm from anomeric proton $(\mathrm{H}-1)$, signals from $\mathrm{H}-4$ of $4-\mathrm{O}-$ sulfated residue at $4.8-4.9 \mathrm{ppm}$, ring proton $\mathrm{H} 2-\mathrm{H} 5$ between 3.6 and $4.7 \mathrm{ppm}$ and prominent signal from methyl proton H-6 at 1.28 ppm. Broad signals between 3.37 and 3.44 ppm could be attributed to $\mathrm{H}-5$ and $\mathrm{H}-2$ in the D-mannopyranose respectively [41]. 
Table 1: Composition and yield of crude fucoidan fractionation by ion-exchange chromatography. Column: DEAE-Sephdex A-25; brown seaweed: S. swartzii

\begin{tabular}{|c|c|c|c|c|c|c|c|c|c|c|c|}
\hline \multirow[b]{2}{*}{ 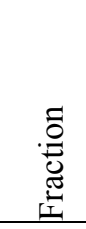 } & \multirow[b]{2}{*}{ 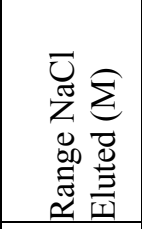 } & \multirow[b]{2}{*}{$\begin{array}{l}00 \\
\frac{0}{0} \\
\vdots \\
j\end{array}$} & \multirow[b]{2}{*}{ 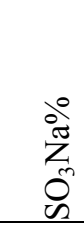 } & \multirow{2}{*}{ 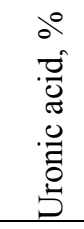 } & \multicolumn{7}{|c|}{ Neutral monosaccharide, $\% \mathrm{~mol}$} \\
\hline & & & & & $\begin{array}{l}0 \\
0 \\
0 \\
0 \\
\end{array}$ & 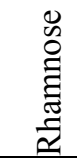 & 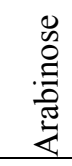 & 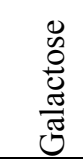 & $\begin{array}{l}0 \\
0 \\
0 \\
0 \\
0 \\
0\end{array}$ & 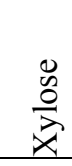 & $\begin{array}{l}0 \\
\mathscr{D} \\
\text { 芯 } \\
\Sigma\end{array}$ \\
\hline Total & - & - & 23.5 & 6.7 & 54.0 & 2.1 & 4.4 & 28.7 & 2.8 & 1.8 & 3.9 \\
\hline $\mathrm{F} 1$ & $0-0.5$ & 2.0 & 5.6 & 15.0 & nd & nd & nd & nd & nd & $\mathrm{Nd}$ & nd \\
\hline $\mathrm{F} 2$ & $0.5-1.0$ & 20.2 & 14.6 & 13.1 & 49.5 & 2.7 & 7.5 & 29.4 & 3.0 & 2.7 & 4.7 \\
\hline F3 & $1.0-2.0$ & 33.3 & 18.4 & 5.5 & 56.0 & 1.9 & 5.2 & 28.9 & 3.2 & 1.9 & 3.0 \\
\hline $\mathrm{F} 4$ & $2.0-2.5$ & 26.2 & 28.0 & 7.6 & 55.6 & 3.3 & 4.1 & 27.9 & 2.8 & 2.4 & 3.6 \\
\hline F5 & $2.5-3.5$ & 16.0 & 42.3 & 1.9 & 57.1 & 2.0 & 4.2 & 27.4 & 2.0 & 0.9 & 4.0 \\
\hline
\end{tabular}

nd - not determined.

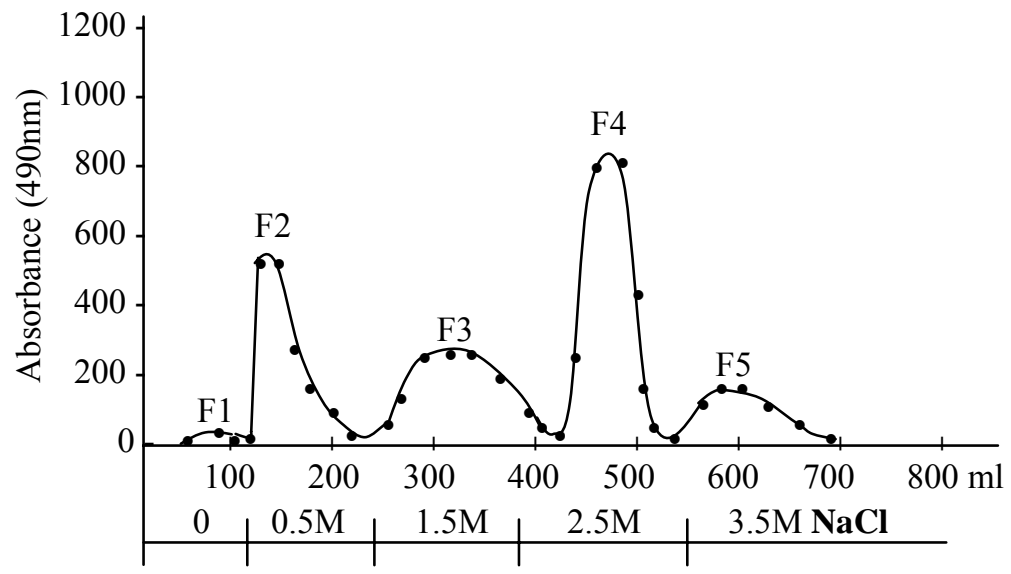

Fig. 3: $\quad$ Fractionation of crude fucoidan isolated from the brown alga S. swartzii on a DEAE-Sephadex A-25 column.

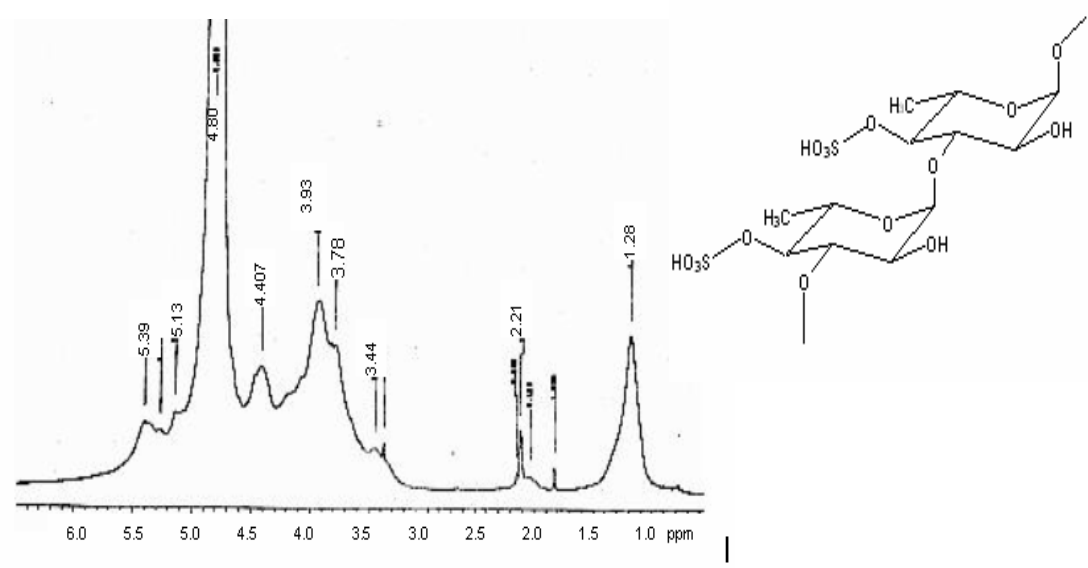

Fig. 4: $\quad H^{1}$ NMR spectrum of the fucoidan fraction 4 isolated from S. mcclurei 
Five fucoidan fractions prepared from S. swartzii by ion-exchange chromatography were tested for anti-invasion activity for breast cancer cells. The experimental results were presented in Fig. 5, where all fucoidan fractions demonstrated activity against cancer cells, while fraction F5 with highest sulfate content showed the strongest anti-invasion activity. This proves that sulfate content may play a pivotal role in the anticancer activity of fucoidans. The dependence of invasiveness of human breast cancer cells MDA-MB-231 on the fucoidan concentration of the fractions F1, F2, F3, F4, F5 was also depicted in Fig. 5, indicating that the fucoidan concentration of $0.5 \mu \mathrm{g} / \mathrm{ml}$ is enough for blocking major part of the cancer cells. The fact that fraction F3 exhibits a lower anti-invasion activity than F1 although its sulfate content is much higher than that of the latter could be explained by the presence of uronic acid which also possesses anticancer properties [5]: uronic acid content of fraction F1 is 15\%, while that of fraction $\mathrm{F} 3$ is $5.5 \%$.

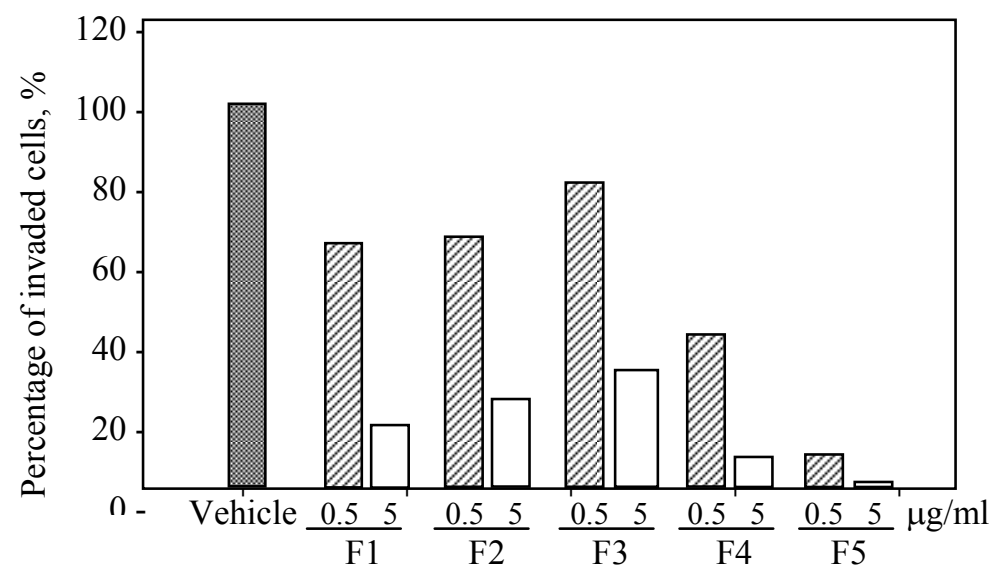

Fig. 5: $\quad$ Invasiveness of human brest cancer cells MDA-MB-231 for different fucoidan fractions prepared from $S$. swrtzii

The effect of the fucoidans isolated from $S$. swartzii on the invasiveness of human breast cancer cells MDA-MB-231 was illustrated in Fig. 6. The pictures show that for the fraction F5 with fucoidan concentration of $0.5 \mu \mathrm{g} / \mathrm{ml}$, almost all the breast cancer cells were inactivated (this experiment was carried out at Korean Research Institute of Biology and Biotechnology).

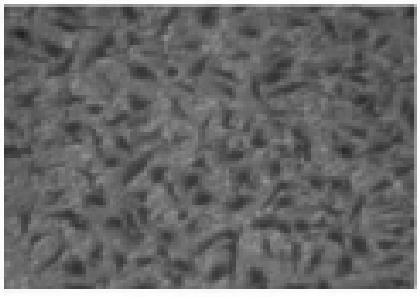

Vechicle

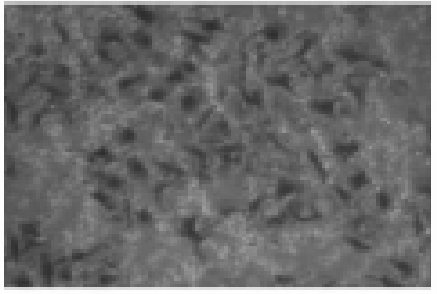

$\mathrm{F} 4(0.5 \mu \mathrm{g} / \mathrm{ml})$

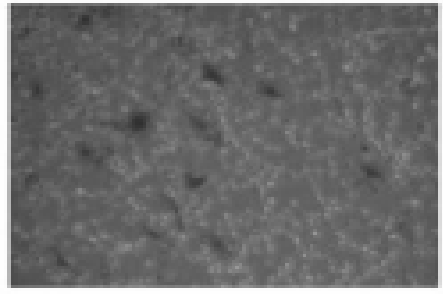

F4 $(0.5 \mu \mathrm{g} / \mathrm{ml})$

Fig. 6: $\quad$ Effects of fucoidan isolated from S. swartzii on the invasiveness of human brest cells MDA-MB-231

At the same time, since 2004 the Nha Trang Branch of Institute of Materials Science, VAST, has carried out the studies on searching fucoidan-containing brown algal species. As the primary results, among 8 brown seaweed samples tested, five species including $S$. polycystum, 
S. oligocystum, S. mcclurei, S. swartzii and denticaprum were found to be effective against some types of cancer such as lung, liver, bladder and colon cancers. At the moment, in IMS Nha Trang Branch a laboratory scale pilot was set for fucoidan production. A block diagram of the small scale pilot for fucoidan production from brown seaweeds is shown in Fig.7.

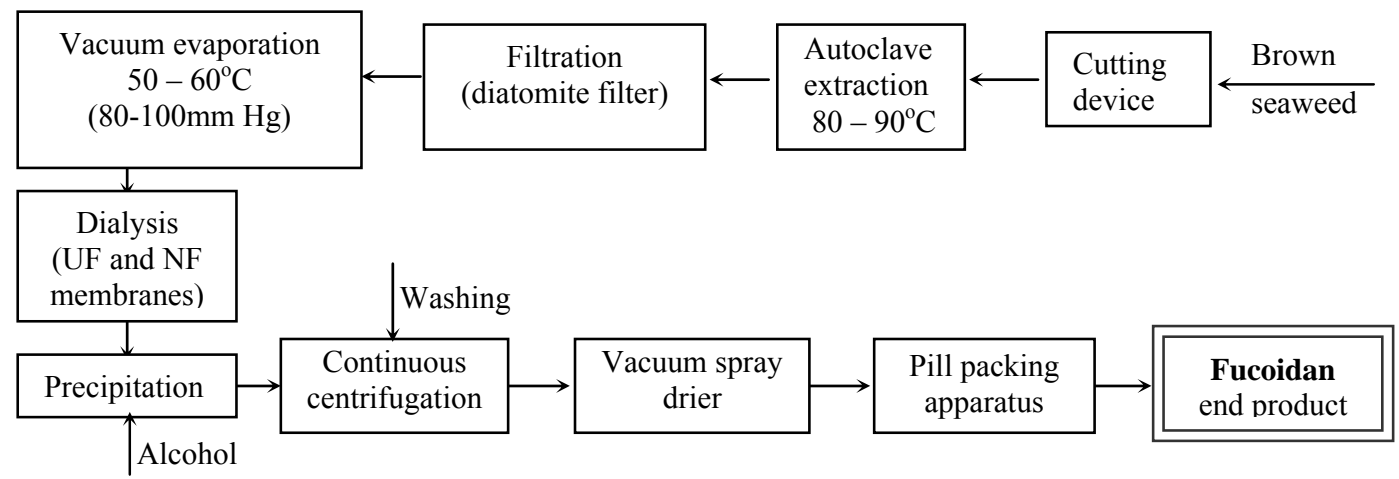

Fig. 7: $\quad$ Block diagram of small scale pilot for fucoidan production from brown algae

\section{CONCLUSIONS}

The fucoidans from some Vietnamese Sargassum species such as S. polycystum, S. oligocystum, S. mcclurei, S. swartzii and denticaprum were extracted and fractionated on a DEAE-Sephadex A-25 anion-exchange column.

The fractionated fucoidans were found to be the sulfated fucogalactans containing sulfate ester groups and uronic acid, and composed essentially of fucose and galactose, as well as a minor amount of other sugars. The polysaccharide fractions obtained were tested for anticancer activity. The primarily obtained results showed that all fucoidan fractions isolated from S. swartzii demonstrate bioactivity effects against breast cancer cells, while fraction F5 with a highest sulfate content exhibits the strongest anti-invasion activity. This indicates that sulfate content may play an important role in the anticancer activity of the brown algal fucoidans.

A laboratory scale pilot for fucoidan production from Vietnamese brown seaweeds has been set with a capacity of $500 \mathrm{~g}$ of crude fucoidan per day.

\section{ACKNOWLEDGEMENT}

This work was supported by KOSEF through the Anticancer Laboratory of Korean Research Institute of Biology and Biotechnology. The authors are grateful to Drs Lee Jeong Hyung and Lee Dong Ho for their help in performing the anti-invasion activity experiment. The authors are also grateful to Dr Le Thi Mai Huong from Institute of Natural Substances Research, VAST, for anticancer testing of the brown algal fucoidan samples.

\section{REFERENCE}

1. Ireland, C.M, Copp, B.R., Foster, M.P., McDonald, L.A., Radisky, D.C., and Swersey, J.C. (1993), Biomedical potential of marine natural products, Pharmaceutical and Bioactive Natural Products, Marine Biotechnology, vol.1, Plenum Press, NY, pp. 1-43. 
2. Kolender, A.A., Matulewicz, M.C., and Cerezo, A.C. (1995), Carbohydr. Res., vol. 273, pp. 179-185.

3. Carlucci, M.J., Scolaro, L.A., and Damonte, E.B. (1999), Chemotheraphy, vol. 45, pp. 429-436.

4. Zviaghinzeva, T.N., Sundukova, E.V., and Elijacova, L.A. (1996), Patent SU 1642725 A1. 10.08.1996.

5. Smit A.J. (2004), A review. J. Appl. Phycology, vol. 30, pp. 1-17.

6. Patankar, M.S., Oehninger, S., Barnett, T., Williams, R.L., and Clark G.F. (1993), J. Biol. Chem., vol. 268, pp. 21770-21776.

7. Berteau, O. and Mulloy, B. (2003), Glycobiology, vol.13, pp. 29R-40R.

8. Bilan, M.I., Grachev, A.A., and Nifantieva, N.E., Usov, A.I. (2004), Carbohydr. Res., vol. 339, pp. 511-517.

9. Chevolot, L., Mulloy B., Ratiskol J., Foucault A., and Colliec-Jouault S. (2001), Carbohydr Res., vol. 330, pp. 529-535.

10. McClure, M.O., Moore, J.P., Blanc, D.F., Scotting, P., Cook, G.M., Keynes, R.J., Weber, J.N., Davies, D., and Weiss, R.A. (1992), AIDS Res. Hum. Retroviruses, vol. 8, pp. 1926.

11. Baba, M., Snoeck, R., Pauwels, R., and De Clerq, E. (1988), Antimicrob. Agents Chemother, vol. 32, pp. 1742-1745.

12. Garcia-Villalon, D. and Gil-Fernandez, C. (1991), Antiviral Res., vol. 15, pp. 139-148.

13. Xiao, L., Yang, C., Patterson, P.S., Udhayacumar, V., and Lal, A.A. (1996), Infect. Immun, vol. 64, pp. 1373-1378.

14. Hahnenberger, R. and Jakobson, A.M. (1991), Glycoconj. J., vol. 8, pp. 350-353.

15. Foxall, C., Watson, S.R., Dowbenko, D., Lasky, L.A., Kiso, M., Hasegawa, A., Asa, D., and Brandley, B.K. (1992), J. Cell Biol., vol. 117, pp. 895-902.

16. Bolwell, G.P., Callow, J.A., Callow, M.W., and Evans, L.V. (1979), J. Cell Sci. vol. 36, pp. 19-30.

17. Ahuja, K.K. (1982), Exp. Cell Res., vol. 140, pp. 353-362.

18. Peterson, R.N., Russell, L.D., and Hunt, W.P. (1984), J. Exp. Zool., vol. 231, pp. 137-147.

19. Pereira, M., Mulloy, B., and Mourao, P.A.S. (1999), J. Biol. Chem., vol. 274, pp. 7656-7667.

20. Venkateswaran, P.S., Millman, I., and Blumberg, B.S. (1989), Planta Med., vol. 55, pp. 265-270.

21. Feldman, S.C., Reynaldi, S., Stortz, C.A., Cerezo, A.S., and Damonte, E.B. (1999), Phytomed, vol. 6, pp. 334-340.

22. Ponce, N.M.A., Pujol, C.A., Damonte, E.B., Flores, M.L., and Stortz, C.A. (2003), Carbohydr. Res., vol. 338, pp. 153-165.

23. Mauray, S., Stenberg, C., Theveniaux, J., Millet, J., Sinquin, C., Tapon-Bretaudiere J., and Fisher A. M. (1995), Thromb. Haemost., vol. 74, vol. 1280-1285.

24. Itoh, H., Noda, H., Amano, H., Zhuang, C., and Mizuno, T. (1993), Anticancer Res., vol. 13, pp. 2045-2052. 
25. Blondin, C., Fisher, E., Boisson-Vidal, C., Kazatchkine, M., and Jozefonvicz, J. (1994), J. Mol. Immunol., vol. 31, pp. 245-253.

26. Chevolot, L., Foucault, A., Chaubet, F., Kervarec, N., Sinquin, C., Fisher, A.M., and Boisson-Vidal, C. (1999), Carbohydr. Res., vol. 319, pp. 154-165.

27. Koyama, N., Sagawa, H., Kobayashi, E., Enoki, T., Wu, H.K., Nishiyama, E., Deguchi, S., Ikai, K., Ohnogi, H., Ueda, M., Kondo, A., and Kato, I. (1999), Patent EP 0888776 A1, 07.01.1999.

28. Riov, D., Colliec-Jovault, S., Pinczon du Sel, D., Bosh, S., Siavoshian, S., Le Bert, V., Tomasoni, C., Sinquin, C., Durand, P., and Roussakis, C. (1996), Anticancer Res., vol. 16, pp. 1213-1218.

29. Tako Masakuni. (2000), Patent EP 0994122 A1, 19.04. 2000.

30. Huynh, Q.N. and Nguyen H.D. (1998), The seaweed resources of Vietnam, In: A.T. Critchley, M. Ohno, Seaweed resources of the World, JICA, Japan, pp. 62-69.

31. Vieira R. P., Mulloy B., and Mourao P.A.S. (1991), J. Biol. Chem., vol. 266, pp. 1353013536.

32. Dubois, M., Gills, K.A., Hamilton, J.K., Rebers, P.A., and Smith, F. (1956), Anal. Chem., vol. 28 , pp. $350-354$.

33. Dodgson, K.S. (1961), Biochem. J., vol. 78, pp. 312-319.

34. Saito, H., Yamagata, T., and Suzuki, S. (1968), J. Biol. Chem., vol. 243, pp. 1536-1542.

35. Bitter, T. and Muir, H.M. (1962), Anal. Biochem., vol. 4, pp. 330-334.

36. Mourao, P.A.S. and Perlin, A.S. (1987), Eur. J. Biochem., vol. 166, pp. 431-436.

37. Nishino, T., Yokoyama, G., Dobashi, K., Fujihara, M., and Nagumo, T. (1989), Carbohydr. Res., vol. 186, pp. 119-129.

38. Mabeau, S., Kloareg, B., and Joseleau (1990), Phytochemistry, vol. 29, pp. 2441-2445.

39. Duarte, M.E.R., Cardoso, M.A. Noseda, M.D., and Cerezo, A.S. (2001), Carbohydr. Res., vol. 333, pp. 281-293.

40. Mulloy, B., Ribeiro, A.C., Alves, A.P., Vieira, R.P., and Mourao, P.A.S. (1994), J. Biol. Chem., vol. 269, pp. 22113-22123.

41. Mulloy, B., Mourao, P.A.S., and Gray, E. (2000), J. Biotechnol., vol. 77, pp. 123-135. 